\title{
DIEL DISTRIBUTION AND MOVEMENT OF SOUND SCATTERING LAYER IN KUROSHIO WATERS, NORTHEASTERN TAIWAN
}

Ming-An Lee

Department of Environmental Biology and Fisheries Science, National Taiwan Ocean University, Keelung, Taiwan, R.O.C.

Ming-Hsiu Chao

Department of Environmental Biology and Fisheries Science, National Taiwan Ocean University, Keelung, Taiwan, R.O.C.

Jinn-Shing Weng

Taiwan Fishery Research Institute, Keelung, Taiwan, R.O.C.

Yang-Chi Lan

Taiwan Fishery Research Institute, Keelung, Taiwan, R.O.C.

Hsueh-Jung Lu

Department of Environmental Biology and Fisheries Science, National Taiwan Ocean University, Keelung, Taiwan, R.O.C., hjlu@mail.sju.edu.tw

Follow this and additional works at: https://jmstt.ntou.edu.tw/journal

Part of the Aquaculture and Fisheries Commons

\section{Recommended Citation}

Lee, Ming-An; Chao, Ming-Hsiu; Weng, Jinn-Shing; Lan, Yang-Chi; and Lu, Hsueh-Jung (2011) "DIEL DISTRIBUTION AND MOVEMENT OF SOUND SCATTERING LAYER IN KUROSHIO WATERS, NORTHEASTERN TAIWAN," Journal of Marine Science and Technology. Vol. 19: Iss. 3, Article 3.

DOI: $10.51400 / 2709-6998.2189$

Available at: https://jmstt.ntou.edu.tw/journal/vol19/iss3/3

This Research Article is brought to you for free and open access by Journal of Marine Science and Technology. It has been accepted for inclusion in Journal of Marine Science and Technology by an authorized editor of Journal of Marine Science and Technology. 


\section{DIEL DISTRIBUTION AND MOVEMENT OF SOUND SCATTERING LAYER IN KUROSHIO WATERS, NORTHEASTERN TAIWAN}

\section{Acknowledgements}

We are grateful to the National Science Council of the republic of China (ROC) for financial support (NSC97-2313-B019-004-MY3). Thanks are also due to Mr. Szu-Chia Kao of the National Taiwan Ocean University who assisted in acoustic analysis for sound scattering layer and Dr. C. T. Shih for reviewing the manuscript. 


\title{
DIEL DISTRIBUTION AND MOVEMENT OF SOUND SCATTERING LAYER IN KUROSHIO WATERS, NORTHEASTERN TAIWAN
}

\author{
Ming-An Lee*, Ming-Hsiu Chao*, Jinn-Shing Weng**, Yang-Chi Lan**, \\ and Hsueh-Jung $\mathrm{Lu}^{*}$
}

Key words: diel vertical movement, sound scattering layer, deep scattering layer, volume scattering strength, Kuroshio.

\begin{abstract}
A 26-hr acoustic observation was carried out on board of the "Ocean Research II" in the Kuroshio waters at $123^{\circ} 09.027^{\prime} \mathrm{E}$, $25^{\circ} 05.019^{\prime} \mathrm{N}$ from August 4 to 5, 2007. Acoustic volume scattering strengths (SVs) were collected by a scientific echo sounder $(\mathrm{EK} 500,38 \mathrm{kHz})$ and diel variations of sound scattering layer were analyzed. The maximum SV of surface scattering layers (SSL) around 20 80 m was observed after dawn, and mean SVs of SSL in nighttime was about $-68 \mathrm{~dB}, 8 \mathrm{~dB}$ higher than that of daytime. Two deep scattering layers (DSL) were found in daytime at depth of 400 500 $\mathrm{m}$ and $600 \sim 700 \mathrm{~m}$, which resulted in mean SVs were about $-72 \mathrm{~dB}$ and $-78 \mathrm{~dB}$, respectively. Two clear diel vertical movements were also detected from these two DSL. A part of these two DSL started to ascend at dusk with a speed of $2.9( \pm 2.1)$ and $3.8( \pm 2.8)$ $\mathrm{cm} / \mathrm{s}$, and stayed at 10 to $120 \mathrm{~m}$ at nighttime, while another part of these DSL remained in the deep layer during daytime. These two DSL started to descend at dawn with a speed of 2.0 $( \pm 1.1)$ to $4.0( \pm 3.8) \mathrm{cm} / \mathrm{s}$, and then stayed at depth of 400 500 $\mathrm{m}$ and $600 \sim 700 \mathrm{~m}$ during daytime, respectively.
\end{abstract}

\section{INTRODUCTION}

The Kuroshio, a major western boundary current in the North Pacific, is a warm current flowing northward along the east coast of Taiwan. It intrudes onto the East China Sea shelf, forming a cold dome at the shelf break near the offshore area northeast of Taiwan $[6,7,13,23]$. The intrusion of Kuroshio into the shelf region of the East China Sea (ECS) has distinct seasonal variation and the Taiwan Warm Current plays a sig-

Paper submitted 03/01/10; revised 05/19/10; accepted 06/11/10. Author for correspondence: Hsueh-Jung Lu (e-mail: hjlu@mail.sju.edu.tw).

*Department of Environmental Biology and Fisheries Science, National Taiwan Ocean University, Keelung, Taiwan, R.O.C.

**Taiwan Fishery Research Institute, Keelung, Taiwan, R.O.C. nificant role in the determination of water properties in the outer shelf associated with the Kuroshio intrusion [18]. Lin et al. [13] used the satellite derived sea surface temperature image to indicate clearly a large-scale anticlockwise frontal cold eddy caused by Kuroshio upwelled water [7], which supplies nutrient to the surface water, and resulting in forming the well known fishing ground for mackerel purse seine and torch-lighted squid fishery $[11,10]$ in the southern ECS. A multidisciplinary oceanographic program, KEEP (Kuroshio Edge Exchange Processes), has been conducted in this water since 1989 [3, 10, 13, 14].

Marine organisms such as plankton and micronekton tend to aggregate at specific depth in the ocean. Knowledge of the distribution and abundance of these organisms is key point to understand the nature and mechanism of ecosystem and possibly to position the fishing grounds. Sampling with a net has been commonly used in studies of these organisms. This approach provides detailed information of species and development stage of plankton, but does not survey an extended scale of time and space. On the other hand, these organisms can scatter acoustic waves as a scattering layer on echogram. This is the so-called sound scattering layer and has been observed in the ocean throughout the world [20]. In other words, acoustic remote sensing technique can be used to detect and identify characteristics of objects by detecting reflections and radiations of targets. It has the ability to survey over a large area rapidly with a low operational cost, and to provide a good estimate of the population. The purpose of this study is to investigate the summer diel variation in mean volume backscattering strength of sound scattering layer and its vertical movement in the Kuroshio water off northeastern Taiwan.

\section{MATERIALS AND METHODS}

\section{Acoustic Monitoring}

A 26-hr acoustic study was carried out on board of the "Ocean Research II" across the shelf waters of southern ECS from August 4 to 5 of 2007 at a station $\left(123^{\circ} 09.027^{\prime} \mathrm{E}\right.$, $25^{\circ} 05.019$ 'N) in the Kuroshio water (Fig. 1). The drogue method was used to monitor the movement of sound scattering 


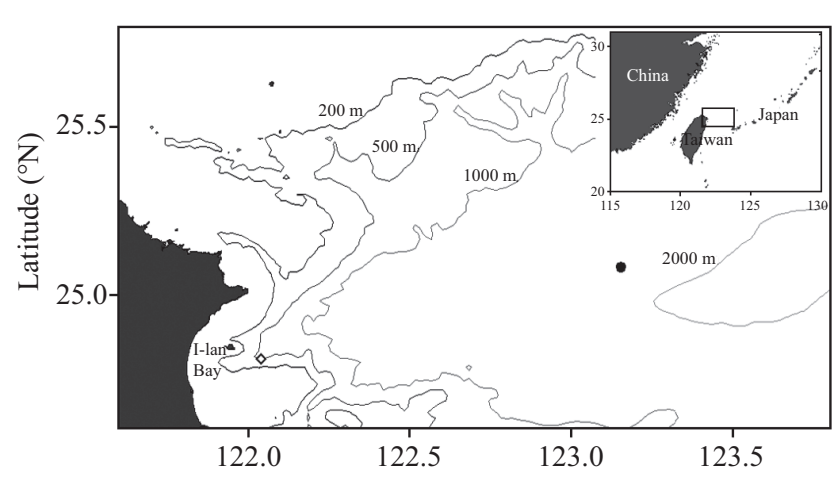

Fig. 1. Survey area and approximate drogue site for acoustic monitoring in Kuroshio water (solid circle) and slope water (open diamond, Chou et al., 1999).

layer. Acoustic data were collected with a scientific echo sounder system (Simrad EK500), using a $38 \mathrm{kHz}$ split beam transducer. The measurement was also conducted for the frequecy of $120 \mathrm{kHz}$, but due to a noise problem the result could not be used for the present analysis. The scattering properties are somewhat different beween 38 and $120 \mathrm{kHz}$, future surveys will be conducted for both frequencies. Echoview post-processing software was used to process the acoustic signals and monitor the diel distribution of sound scattering layer. The parameters of echo sounder were absorption coefficient $(10 \mathrm{~dB} / \mathrm{km})$, pulse repetition rate $(0.5 \mathrm{ping} / \mathrm{s})$, pulse duration $(1.0 \mathrm{~ms})$, sampling distance $(10 \mathrm{~cm})$, half beam angle $\left(-3 \mathrm{~dB}=7.1^{\circ}\right)$, SV threshold $(-90 \mathrm{~dB})$, and band width $(3.8$ $\mathrm{kHz}$ ). In the laboratory, the echo signals of sound scattering layer including SSL and DSL were post processed so that each data point represented an average of $5 \mathrm{~m}$ of depth and sampled over 2 min (60 pings). The mean SV data provided a convenient measure of the density index of sound scattering strength, as the species with its target strength was uncertain. The SV echograms of the water column for 26 hours were plotted by the software package of Echoview, version 2.1, and used as a biomass index of the sound scattering layer.

Vertical velocities of DSL were estimated independently from the slopes of the principal volume scattering layers. During the period of diel vertical migration, individual DSL was isolated subjectively on a display monitor using the postprocessing software. We used more strict threshold $(-80 \mathrm{~dB})$ to determine the boundary of the main part of a DSL, then used echogram edit function to draw a region as an isolated DSL. Finally, cut the region into segments by 1 minute per interval and then exported the center depth of each segment. From each isolated DSL, the center depth of each segment was calculated as a function of time, $\mathrm{D}(\mathrm{t})$. The vertical migration velocity (Vs) was then estimated from the rate of change in DSL as the derivative of $\mathrm{D}(\mathrm{t})$ with respect to time $(\mathrm{t})$ : Vs $=$ $\mathrm{dD}(\mathrm{t}) / \mathrm{dt}$.

\section{Oceanographic Condition}

A seabird CTD system (Model SBE 911) was used to obtain

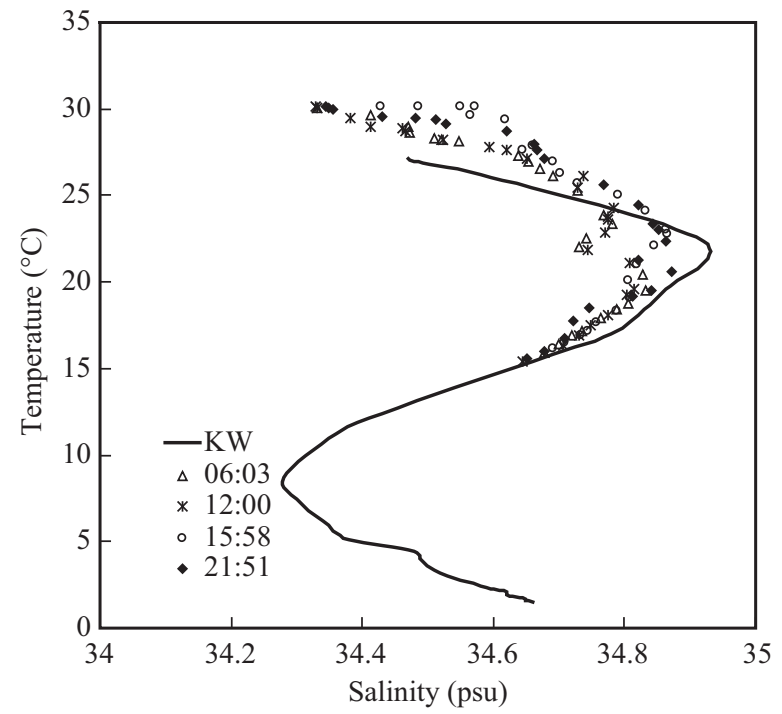

Fig. 2. Temperature and salinity diagram. Solid line represents the $T / S$ curve of Kuroshio water observed by Matsuno et al. [5]. Different symbols show the T/S observations at different times on August 4, 2007.

temperature, salinity, and density profiles (depth range from $0 \mathrm{~m}$ to $250 \mathrm{~m}$ ) at 6-hour intervals during the acoustic drogue periods. The initial raw CTD data were processed onboard the ship by the SeaSoft package, and then T/S diagrams were subsequently plotted using the software of Excel. The CTD system was calibrated prior to and after the cruises at the vessel operation center of R\&D office, National Taiwan Ocean University. Accuracies for temperature and salinity were estimated to be $0.01^{\circ} \mathrm{C}$ and $0.01 \mathrm{psu}$, respectively.

\section{RESULTS}

\section{Oceanographic Condition}

Temperature and salinity (T/S) diagrams from surface to $250 \mathrm{~m}$ depth at the fixed station in August, 2007 are plotted in Fig. 2. Water temperature ranged from 15.4 to $30.4^{\circ} \mathrm{C}$, and salinity ranged from 34.33 to 34.88 psu. Hydrographic characteristics of T/S profiles at 4 time points $(06: 03,12: 00,15: 58$, and 21:51) were similar and matched with the T/S curve of Kuroshio Water measured by Matsuno et al. [18].

\section{Volume Backscattering Strength of Sound Scattering Layer}

Fig. 3 showed the diel variation in mean volume backscattering strength of sound scattering layer in the Kuroshio waters during the period of August 4 to 5, 2007. Diel differences were observed in the vertical distribution of backscattering (Fig. 4). It showed that there are three higher acoustic scattering layers about $-76,-72.1$ and $-78.6 \mathrm{~dB}$ at depths of $20 \sim 80$ $\mathrm{m}, 420 \sim 500 \mathrm{~m}$ and $600 \sim 700 \mathrm{~m}$ in daytime, respectively. From echogram in Fig. 3, the mean SV of SSL around 20 to $150 \mathrm{~m}$ at night was about $-68 \mathrm{~dB}, 8 \mathrm{~dB}$ higher than that in daytime. 


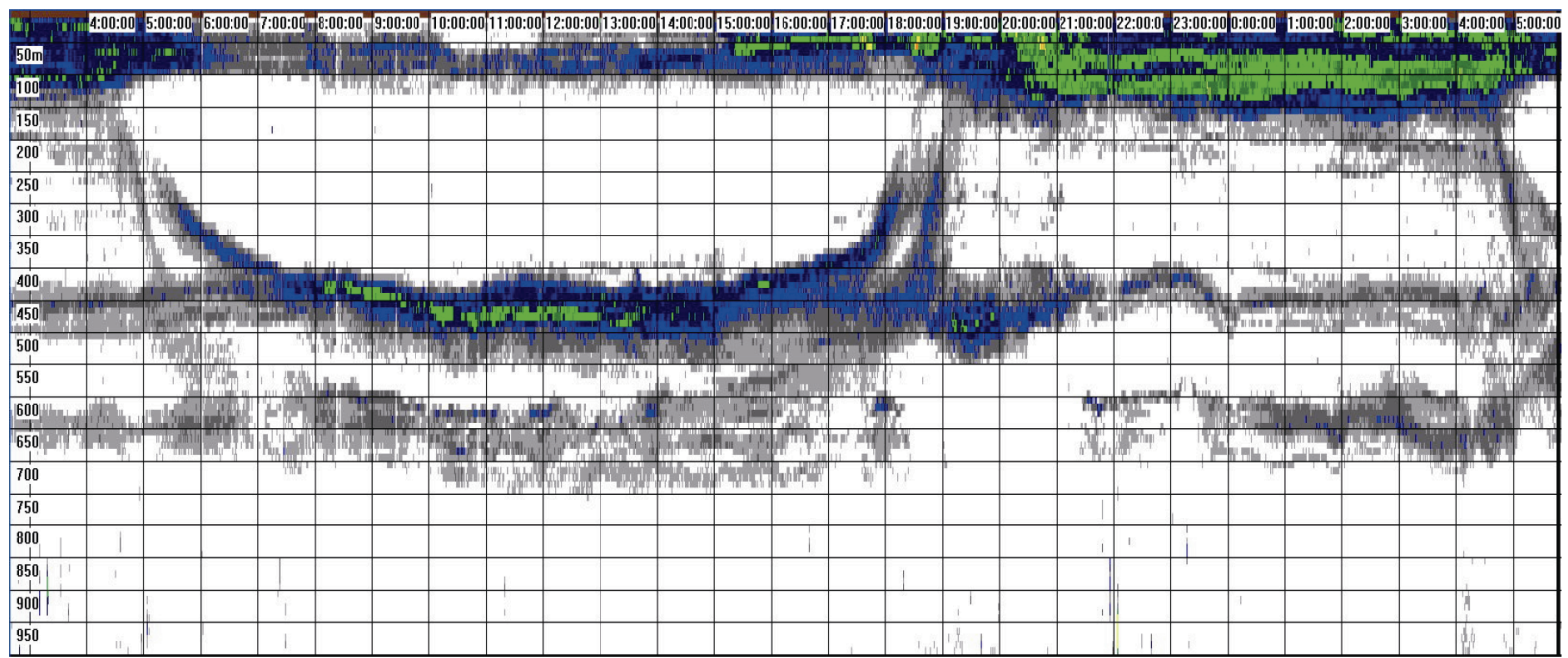

Fig. 3. The diel variation in mean volume backscattering strength of sound scattering layer in the Kuroshio waters, northeastern Taiwan. The color bar indicated the scale of volume scattering strengths.

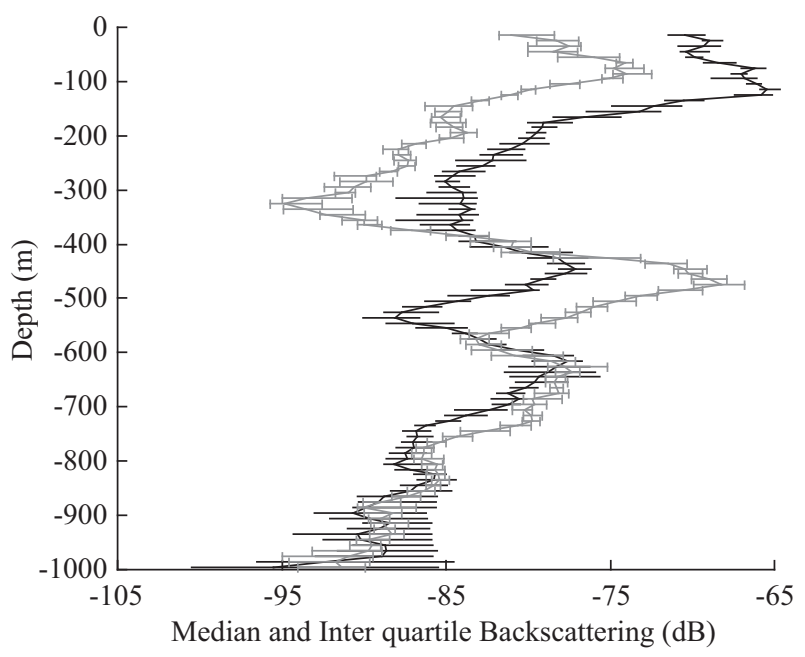

Fig. 4. Vertical distribution of backscattering in the Kuroshio water during daytime (09:00 15:00, gray solid line) and nighttime (19:00 03:00, black dotted line). Median and inter-quartile range (indicated by gray and black error bars in day and night, respectively) of backscattering were calculated in 10-m depth intervals.

The mean SV distribution also exhibits two distinct kinds of DSL, which indicates clear diel vertical movement (DVM) and resident distribution. For the latter, they stayed stably at the depths of ca 400 to $500 \mathrm{~m}$ and ca 600 to $700 \mathrm{~m}$, respectively. The mean SV of these two DSLs during the night time was estimated about -78 and $-79 \mathrm{~dB}$, respectively. For the former, two clear DSLs with DVM pattern were recorded in Fig. 3. Both layers, here referred to as upper and lower layers, were aggregated at deep water during daytime and move into shallow water at night. The mean SV of two DSLs in daytime (09:00 15:00) at depth of 400 500 $\mathrm{m}$ and 600 700 m were $-72.1 \mathrm{~dB}$ and $-78.6 \mathrm{~dB}$, which is $5.6 \mathrm{~dB}$ higher and $0.1 \mathrm{~dB}$ lower than that during nighttime (19:00 03:00), respectively.
Under $800 \mathrm{~m}$ deep, however, backscattering was generally weak and decreased from $-85 \mathrm{~dB}$ to $-95 \mathrm{~dB}$ with depth.

Except for the periods of ascending and descending, the vertical thickness of upper and lower DSLs in the daytime were varied about 130 160 m and 150 175 m, with $60 \sim 140 \mathrm{~m}$ and $80 \sim 130 \mathrm{~m}$ higher than those in nighttime, respectively.

\section{DVM and Mmigration Velocity}

Due to the difficulties on DSL and SSL echograms identification in shallower water, central depths of two major parts of DSLs larger than $200 \mathrm{~m}$ deep were estimated and shown in Fig. 5. The migration velocities of these two DSLs were estimated in Fig. 6. The echogram in Fig. 3 showed the lower DSL started to descend at 4:30 with a maximum speed of $13.72 \mathrm{~cm} / \mathrm{s}$, and then decrease subsequently the descending speed to 8.97 and $3.29 \mathrm{~cm} / \mathrm{s}$ at 5:00 and 6:00, respectively. The maximum descending speed of $4.71 \mathrm{~cm} / \mathrm{s}$ for upper DSL was found at 5:00, and its mean speed was $2.0( \pm 1.1) \mathrm{cm} / \mathrm{s}$. As these two DSLs, upper layer and lower layer, returned to their regular depth at daytime, their vertical movement speed was varied slightly with mean speed $0.1( \pm 0.1)$ and $0.3( \pm 0.1) \mathrm{cm} / \mathrm{s}$, respectively. After dusk, both DSLs started to ascend. The lower DSL seemed to move vertically at 16:20, 40 minutes earlier than that of the upper layer. After 17:00, the movement speed of the lower DSL was subsequently faster than that of upper layer. The mean acending speed of lower DSL was 3.8 $( \pm 2.8) \mathrm{cm} / \mathrm{s}$. The maximum ascending speeds for upper and lower DSL were 7.6 and $10.7 \mathrm{~cm} / \mathrm{s}$, respectively.

\section{DISCUSSION AND CONCLUSION}

Our results were similar to those reported by Balino and Aksnes [2] for the DVM of sound scattering layer in Masfjorden, western Norway. Two distinct sound scattering layers at depth of 100 and $150 \mathrm{~m}$ were recorded in their study. These 


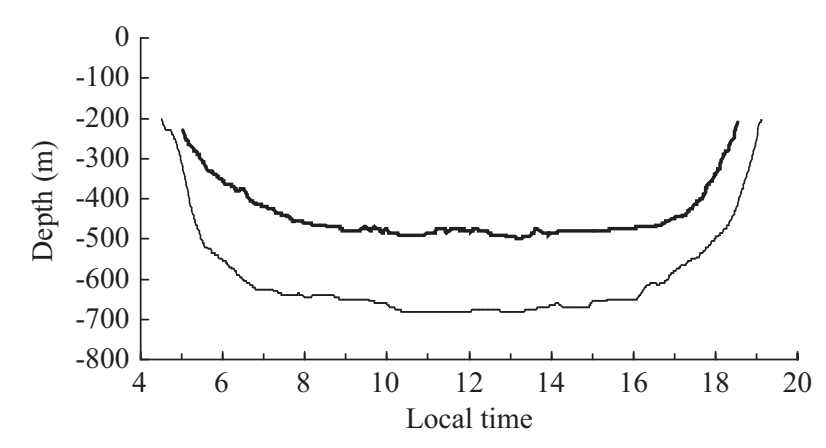

Fig. 5. Central depth of two major parts of DSLs. Solid line: upper DSL; dotted line: lower DSL.

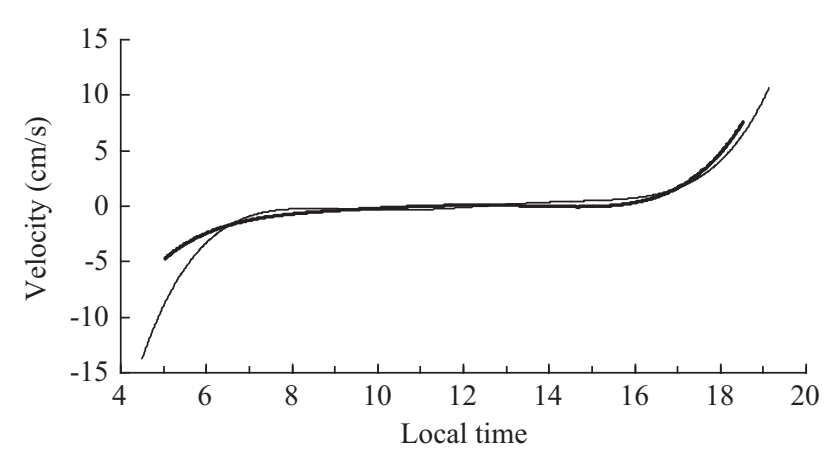

Fig. 6. Vertical velocities estimated from the slope of the SSL. Solid line: upper DSL; dotted line: lower DSL.

two layers showed clear DVM including ascending and descending movements. The ascending movement started at dusk and reached the shallowest water during night-time, while the descending movement occurred at dawn and gradually returned to its habitual depth during daytime. This kind of DVM was the most common nocturnal vertical migration, where groups of marine organisms ascend around dusk and remain at a shallower depth during the night. Around dawn, they begin to descend and remain at depth during the day [5]. A nocturnal vertical migration of DSL dominated in the two species, Sergia lucens and Pasiphaea japanicus, in I-lan Bay was reported by Chou et al. [4]. Similar phenomenon was also found in DSL dominated mesopelagic fish such as lanternfish and myctophid fish with a clear nocturnal vertical migration by ascending to surface during night time and descending to habitual depth during daytime [8]. For example, concentrations of northern lantern fish in Oregonian and Californian waters moved between depths of 20 30 $\mathrm{m}$ at night, and 600 $700 \mathrm{~m}$ during day time [24].

It is interesting that one part of these two DSL started to ascend at dusk and stay in surface water at nighttime, while the other part of these DSLs remained in deep layer day and night. It means that except for DVM the SV distribution also exhibits another kind of deep scattering backscatter, which almost stays at the same depth and belongs to resident distribution. This may coincide with the results of Balino and Aksnes [2] who thought part of sound scattering layer did not react as an
Table 1. Estimated velocity of sound scattering layer in this study and related references.

\begin{tabular}{|c|c|c|c|}
\hline Survey area & Target & $\begin{array}{c}\text { Estimated mean } \\
\text { velocity }(\mathrm{cm} / \mathrm{s})\end{array}$ & References \\
\hline Kuroshio water & DSL & $\begin{array}{c}\text { Upper layer: } \\
2.6 \sim 3.1 \\
\text { Lower layer: } \\
3.8 \sim 4.2\end{array}$ & This study \\
\hline I-Lan Bay & DSL & $2.33 \sim 3.17$ & Chou et al. [4] \\
\hline Arabian Sea & DSL & $2.78 \sim 12.5$ & Ashjian et al. [1] \\
\hline Oshima Peninsula & DSL & $1.67 \sim 5$ & Iida et al. [12] \\
\hline western Norway & DSL & 2.5 (Max.) & Balino and Aksnes [2] \\
\hline Arabian Sea & $\begin{array}{c}\text { Zooplankton } \\
\text { Fish }\end{array}$ & $\begin{array}{c}8(\text { Max. }) \\
13 \text { (Max.) }\end{array}$ & Luo et al. [15] \\
\hline Northeast Atlantic & zooplankton & $2 \sim 6$ & Heywood [9] \\
\hline
\end{tabular}

unit to changes in environment (i.e. light), therefore, the center of the layer remained roughly at the same depth during day hours [2]. A similar phenomenon happens to non-migrants such as Symbolophorus nannochir, which occurs mainly at 500 700 $\mathrm{m}$ both day and night [24]. In addition semi-migrants (i.e. $S$. leucopsarus) and passive migrants (Lampanyctus jordani) were also reported. Due to the lack of proper biological sampling gear, it is difficult to examine which types of species belong to migrants or non-migrants in this water.

In this study the starting time of ascending was earlier in lower DSL than in upper layer by about 30 to 40 minutes, so was the descending time. The initial descending speed when it left the SSL was about $13.7 \mathrm{~cm} / \mathrm{s}$ in shallower water and subsequently decreased to $0.3( \pm 0.1) \mathrm{cm} / \mathrm{s}$ in deep water, while the ascending speed increased subsequently till $10.7 \mathrm{~cm} / \mathrm{s}$ before merged into the SSL. These phenomena suggested that DVM of both DSLs in this water are controlled by light/dark cycle. Balino and Aksnes [2] found that sound scattering layer exhibited a pre-dawn rise before light could be detected $(<0.01$ $\left.\mu \mathrm{E} \mathrm{m}^{-2} \mathrm{~S}^{-1}\right)$ in the morning, prior to the start of its downward displacement. Their results hinted that the adjustment of day depth of the scattering layers was positively proportional to the rate of change in the logarithm of surface light and inversely proportional to the extinction coefficient of the water. The vertical movement speed was also varied with and depended on the dominant species and geographical locations (Table 1). Chou et al. [13] found that Sergia lucens and Pasiphaea japanicus in I-lan Bay near our investigation site were not affected by strong temperature and salinity changes, and showed nocturnal vertical movement by ascending to the surface at night and descending to the deeper habitual depth in daytime. They hinted the starting time of nocturnal movement of $S$. lucens and P. japanicus varied with seasons and were controlled by light and water transparency.

Light is agreed to be the most significant external cue in 
DVM behavior, because time of migration usually corresponds with time of change in light intensity under water at sunrise and sunset [19]. In spite of decades of study, however, the proximate factors that directly stimulate the rise and descent of zooplankton, as well as the ultimate factors (biological advantages) of DVM, are still debated. The predator evasion hypothesis is another ultimate factor, which supposes that migration out of the well-illuminated surface layer during daytime substantially decreases mortality of descending animals by reducing the risk of being detected by visually hunting predators [26]. However, there are likely other reasons why zooplankton benefit by performing DVM, e.g., utilization of oceanic flow field for their horizontal displacement or retention $[16,17]$. DVM also may relate to change and age of ecosystem. Voss et al. [22] investigated DVM patterns of Baltic sprat larvae for the periods 1989 1990 and 1998 2002. They found that this behavioral change coincided with a more general change in the Baltic ecosystem, i.e. an increase in near-surface temperature and a general increase in abundance of the major prey organism of Baltic sprat larvae, with more pronounced aggregation of these larvae in surface waters. Is it an aggregation of the prey or the predator? Willis and Pearcy [25] indicated that common lantern-fish (Stenobrachius leucopsarus) of length 15 20 mm (age 0) are the most abundant in depth range 400 480 $\mathrm{m}$ during the day time and are non-migrants. However, those of length 30 to $40 \mathrm{~mm}$ (age 1) usually occur at depths of about $300 \mathrm{~m}$ by day and migrate to the upper $30 \mathrm{~m}$ layer at night.

The mean SV of upper DSL in daytime were about $-72.1 \mathrm{~dB}$, $5.7 \mathrm{~dB}$ higher than that in daytime, while the mean $\mathrm{SV}$ of lower DSL were about $-78.6 \mathrm{~dB}, 0.1 \mathrm{~dB}$ lower than that in nighttime. According to the equation $\rho=10^{\text {(SV-TS)/10 }}$ and the hypothesis of the constant TS (target strength), it seemed that mean packing density was almost similar during the DVM period of lower DSL. A similar phenomenon noted by Taylor [21] that some mesopelagic organisms lacking swim bladders, like bathylagids, argentinids, stomiatoids, and melamphids, will not scatter the sound. We speculate that this may be the reason why the mean SV in lower DSL was no difference during the DVM period, and on the contrary the mean SV of SSL around 10 to $160 \mathrm{~m}$ in nighttime was about $-68 \mathrm{~dB}, 8 \mathrm{~dB}$ higher than that in daytime. However, further biological sampling data is necessary to confirm this.

The SV records showed a slight increase of the marine organisms (e.g. zooplankton) concentrations towards the surface. And the density in upper DSL in daytime was about four times higher than that in nighttime, while the density in SSL in nighttime was about six times higher than that in daytime. This is similar to the report of Iida et al. [12] in Kuroshio and Oyashio waters. They found the mean SV of the SSL increased from $-80 \mathrm{~dB}$ at the beginning of the ascent to $-50 \mathrm{~dB}$ at the end of the vertical migration. Chou et al. [4] also suggested that the predator with high swimming speed will be attracted by these forages. It can be explained by the fact that the predator and micro-organisms in deeper waters succes- sively join the SSL at dusk and form dense aggregations of marine organisms. However, it is still difficult to estimate the biomass of SSL and DSL, as the DSL contains both vertically migrating and non-migrating species, and the difficulty is lack of proper biological gear in this study.

\section{ACKNOWLEDGMENTS}

We are grateful to the National Science Council of the republic of China (ROC) for financial support (NSC97-2313-B019-004-MY3). Thanks are also due to Mr. Szu-Chia Kao of the National Taiwan Ocean University who assisted in acoustic analysis for sound scattering layer and Dr. C. T. Shih for reviewing the manuscript.

\section{REFERENCES}

1. Ashjian, C. J., Smith, S. L., Flagg, C. N., and Idrisi, N., "Distribution, annual cycle, and vertical migration of acoustically derived biomass in the Arabian Sea during 1994-1995," Deep-Sea Research II, Vol. 49, pp. 2377-2402 (2002).

2. Balino, B. M. and Aksnes, D. L., "Winter distribution and migration of the sound scattering layers, zooplankton and micronekton in Masfjorden, western Norway," Marine Ecology Progress Series, Vol. 102, pp. 35-50 (1993).

3. Chou, H. C., Gong, G. C., Kao, S. J., and Chang, J., “Cross-shelf Distribution of Summer Dinoflagellate abundance in the East China Sea and its correlation to environmental factors," Journal of Fisheries Society of Taiwan, Vol. 32, No. 2, pp. 87-100 (2005).

4. Chou, S. C., Lee, M. A., and Lee, K. T., "Diel vertical movement of the deep scattering layer on the continental slope of I-Lan Bay, Taiwan," Fisheries Science, Vol. 65, No. 5, pp. 694-699 (1999).

5. Cisewski, B., Strass, V. H., Rhein, M., and Kragefsky, S., "Seasonal variation of diel vertical migration of zooplankton from ADCP backscatter time series data in the Lazarev Sea, Antarctica," Deep-sea Research I, Vol. 57, pp. 78-94 (2010).

6. Fan, K. L., "On the upwelling off northeastern shore of Taiwan," Acta Oceanographica Taiwanica, Vol. 11, pp. 105-117 (1980).

7. Gong, G. C., Shiah, F. K., Liu, K. K., Chuang, W. S., and Chang, J., "Effect of the Kuroshio intrusion on the chlorophyll distribution in the southern East China Sea during spring 1993," Continental Shelf Research Vol. 17, No. 1, pp. 79-94 (1997).

8. Gorbatenko, K. M. and Il'Insky, E. N., "Food habits of the most abundant mesopelagic fishes in the Bering Sea," Voprosy ikhtiologii, Vol. 31, pp. 816-821 (1991).

9. Haywood, K. J., "Diel vertical migration of zooplankton in the Northeast Atlantic," Journal of Plankton Research, Vol. 18, No. 2, pp. 163-184 (1996).

10. Hsieh, F. J., Lee, M. A., Oan, J. Y., Wang, Y. T., Lan, K. W., and Lan, Y. C., "Winter distribution and composition of ichthyoplankton associated with thermal front on the continental shelf of the southern East China Sea," Journal of Fisheries Society of Taiwan, Vol. 34, No. 1, pp. 69-85 (2007).

11. Huang, J. B. and Chiu, T. S., "Seasonal and hydrographic variations of ichthyoplankton density and composition in the Kuroshio Edge Exchange Area off northeastern Taiwan," Zoological Studies, Vol. 37, No. 1, pp. 63-73 (1998)

12. Iida, K., Mukai, T., and Hwang, D. J., "Relationship between acoustic backscattering strength and density of zooplankton in the sound-scattering layer," ICES Journal of Marine Science, Vol. 53, pp. 507-512 (1996).

13. Lin, C. Y., Shyu, C. Z., and Shih, W. H., "The Kuroshio Fronts and cold eddies off northeastern Taiwan observed by NOAA-AVHRR imagery," 
Terrestrial; Amospheric and Oceanic Sciences, Vol. 3, pp. 225-242 (1992).

14. Liu, K. K., Peng, T.H., Shaw, P. T., and Shiah, F. K., "Circulation and biogeochemical processes in the East China Sea and the vicinity of Taiwan: an overview and a brief synthesis," Deep-Sea Research II, Vol. 50, pp. 1055-1064 (2003).

15. Luo, J. G., Ortner, P. B., Forcucci, D., and Cummings, S. R., "Diel vertical migration of zooplankton and mesopelagic fish in the Arabian Sea," Deep-Sea Research II , Vol. 47, pp. 1451-1473 (2000).

16. Manuel, J. L. and O'Dor, R. K., "Vertical migration for horizontal transport while avoiding predators: I. A tidal/diel model," Journal of Plankton Research, Vol. 19, pp. 1929-1947 (1997).

17. Manuel, J. L., Pearce, C. M., and O’Dor, R. K., "Vertical migration for horizontal transport while avoiding predators: II. Evidence for the tidal/diel model from two populations of scallop (Placopecten magellanicus) veligers," Journal of Plankton Research, Vol. 19, pp. 1949-1973 (1997)

18. Matsuno, T., Lee, J. S., and Yanao, S., "The Kuroshio exchange with the South and East China Seas," Ocean Science, Vol. 5, pp. 303-312 (2009).

19. Rogachev, K. A., Carmack, E. C., and Salomatin, A. S., "Recent thermohaline transition in the Pacific western subarctic boundary currents and their fresh core eddies: the response of sound-scattering layers," Journal of Marine Systems, Vol. 26, pp. 239-258 (2000).
20. Sameoto, D. D., "Zooplankton and micronekton abundance in acoustic scattering layers on the Nova Scotian slope," Canadian Journal of Fisheries and Aquatic Sciences, Vol. 39, pp. 760-777 (1982).

21. Taylor, F. H. C., "The relationship of midwater trawl catches to sound scattering layers off the coast of northern British Columbia," Journal of the Fisheries Research Board of Canada, Vol. 25, No. 3, pp. 457-472 (1968).

22. Voss, R., Schmidt, J. O., and Schnack, D., "Vertical distribution of Baltic sprat larvae: changes in patterns of diel migration?" ICES Journal of Marine Science, Vol. 64, pp. 956-962 (2007).

23. Wang, G. T. F., Chao, S. Y., Li, Y. H., and Shiah, F, K., "The Kuroshio edge exchange processes (KEEP) study- an introduction to hypotheses and highlights," Continental Shelf Research, Vol. 20, pp. 335-347 (2000).

24. Watanabe, H., Moku, M., Kawagichi, K., Ishimaru, K., and Ohno, A., "Diel vertical migration of myctophid fishes (Family Myctophidae) in the transitional waters of the western North Pacific," Fishery Oceanography, Vol. 8, No. 2, pp. 115-127 (1999).

25. Willis, J. M. and Pearcy, W. G., "Spatial and temporal variations in the Population size structure of three Lanternfishes (Myctophidae) off Oregon, USA," Marine Biology, Vol. 57, pp. 181-191 (1980).

26. Zaret, T. M. and Suffern, J. S., "Vertical migration in zooplankton as a predator avoidance mechanism," Limnology and Oceanography, Vol. 21, pp. 804-813 (1976) 